\title{
Larger offspring associated with lower temperatures across species of Microporella, a widespread colonial invertebrate
}

\author{
Emanuela Di Martino ${ }^{1, *}$, Lee Hsiang Liow ${ }^{1,2}$ \\ ${ }^{1}$ Natural History Museum, University of Oslo, Blindern, PO Box 1172, Oslo 0318, Norway \\ ${ }^{2}$ Centre for Ecological and Evolutionary Synthesis, Department of Biosciences, University of Oslo, Blindern, PO Box 1066, \\ Oslo 0316, Norway
}

\begin{abstract}
Among life history traits, offspring size has one of the most direct impacts on fitness, influencing growth, recruitment and survival of the individual, therefore affecting population, and ultimately macroevolutionary outcomes. Despite its ecological and evolutionary importance, little is known about how offspring size varies in lineages over macroevolutionary timescales, especially for colonial organisms. Here, we use the cheilostome bryozoan genus Microporella to investigate variation in offspring size over the history of the lineage. The genus Microporella is species-rich, cosmopolitan, has a calcified skeleton (and is hence readily preserved in the fossil record), and is a brooder. The brood structure (ovicell) reliably reflects the space occupied by a larva and hence ovicell size is a good proxy for offspring size. Using a suite of biotic and abiotic factors, we ask what best explains offspring/larval size variation in contemporary and fossil species of Microporella, and how offspring/larval size changes through the millions of years of the history of the lineage. We find that offspring size is affected by a combination of module size and water temperature (or latitude when fossil species are included), while fecundity and levels of nutrients have a weak to no effect on this life history trait. Among Microporella species, descendant species are statistically more likely to have larger offspring than their putative ancestors, with the size difference between species pairs little explained by temporal latitudinal shifts. Our results suggest that both contemporary ecological controls and historical considerations are important in understanding life history trait evolution.
\end{abstract}

KEY WORDS: Bryozoa - Larval size - Fecundity · Latitude $\cdot$ Sea surface temperature $\cdot$ Bergmann's rule . Atkinson's rule $\cdot$ Cope's rule

${ }^{*}$ Corresponding author: e.d.martino@nhm.uio.no

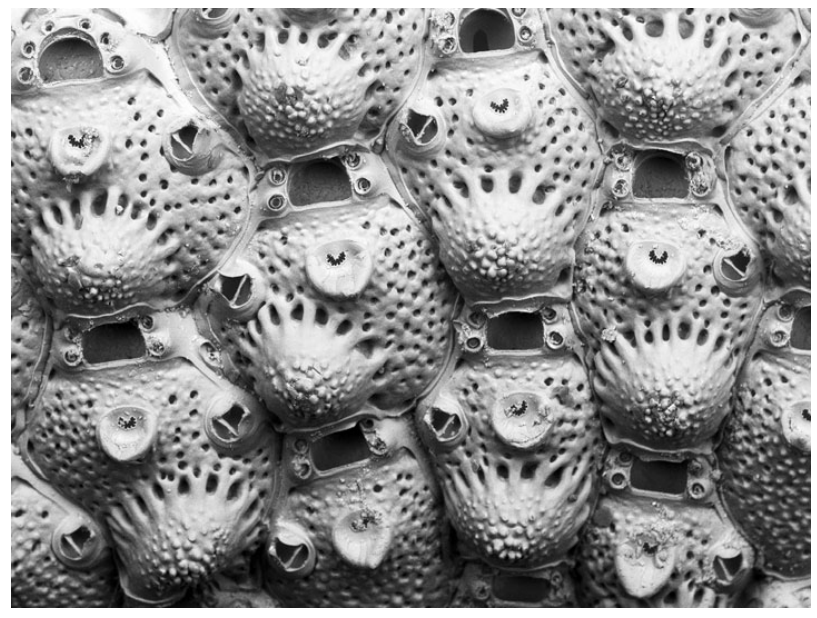

Scanning electron micrograph of fertile zooids of a contemporary species of the cheilostome bryozoan genus Microporella from New Zealand (magnification: 50x).

Photo: Emanuela Di Martino

\section{INTRODUCTION}

Life history traits have direct impact on both the fitness of the individuals involved and the growth and decline of the populations to which they belong (Stearns 1992, Marshall \& Keough 2008). As such, life history traits, including reproductive strategies (e.g. sexual versus asexual reproduction, sexual dimorphism and investment in offspring), can also influence macroevolutionary outcomes, such as extinction probability (O'Dea et al. 2007, Martins et al. 2018). In solitary organisms, offspring size often trades off with fecundity, i.e. the number of offspring produced (e.g. Ramirez Llodra 2002, Marshall et al. 2018a) and

() The authors 2021. Open Access under Creative Commons by Attribution Licence. Use, distribution and reproduction are unrestricted. Authors and original publication must be credited. 
is modulated by the ecological challenges present in the environment and the constraints imposed by the biology of the organism in question (e.g. Strathmann \& Strathmann 1982, Strathmann et al. 1984). Our understanding of the historical covariance of marine offspring and adult size is largely informed by work on solitary organisms, including mollusks (e.g. Jablonski \& Lutz 1983) and echinoderms (e.g. Jeffery \& Emlet 2003), where the size (and hence feeding capabilities) of larvae have evolutionary implications. However, colonial metazoans, which represent a major component of marine global biodiversity (Jackson 1977), often do not fit well into the ecological and evolutionary models developed for unitary organisms (e.g. Jackson 1985, Hiebert et al. 2020), hence the necessity of performing quantitative studies and/or testing model predictions directly on colonial organisms. The paucity of studies on offspring size of colonial invertebrates (e.g. cnidarians, bryozoans, ascidians, and sponges) over macroevolutionary timescales is partly due to the extremely low preservation potential of marine larvae in the fossil record (Raff et al. 2006), i.e. we have to rely on inferences made from extant organisms.

Here, we overcome this obstacle by using the size of the skeletal brooding structures (ovicells), a reliable proxy for offspring/larval size (Herrera \& Jackson 1996), to investigate offspring/larval size evolution in the species-rich, cosmopolitan cheilostome bryozoan genus, Microporella Hincks, 1877. Microporella includes, to date, 149 described species (Bock 2020), 33 of which are exclusively found as fossils. Like all cheilostome bryozoans, Microporella is marine, with the great majority of species having encrusting colonies of indeterminate, extensive, sheetlike growth, and has a calcified skeleton where ovicells in mature colonies brood 1 larva at a time (see Fig. 1). Its larvae, like that for the great majority of cheilostomes, are non-feeding and thought to settle within hours to a couple of days at most (e.g. d'Hondt 1977). The morphology of its feeding modules (i.e. autozooids, henceforth simply 'zooids'), with the characteristic combination of porous frontal surface, semielliptical orifices, ascopore and often lateral adventitious avicularia (see Fig. 1), makes Microporella one of the most distinctive bryozoan genera. Microporella spans latitudes from the equator to $80^{\circ}$ (Taylor \& Mawatari 2005) in both the northern and southern hemispheres and can be found living in the intertidal zone (e.g. Dick et al. 2005) down to the deep waters of the continental slope (e.g. Figuerola et al. 2018). In Microporella, as in many cheilostomes, large zooid size has shown to be advantageous in competition for living space (Liow et al. 2017, 2019), and zooid size evolution seems to conform to Cope's rule, normally applicable to the body size of solitary organisms (e.g. Heim et al. 2015), where descendant species frequently have larger zooid size than ancestral species (Liow \& Taylor 2019). Likewise, a study based on a few species within several different genera (including Microporella) suggests that zooid size in cheilostomes may conform to Bergmann's rule, with contemporary species from higher latitudes showing larger zooid size than congeneric species from lower latitudes (Kukliński \& Taylor 2008). However, a relationship between zooid size and ambient water temperature at the time the zooids are built (i.e. Atkinson's rule), with larger zooids being produced in colder waters and smaller zooids being produced in warmer waters, empirically valid for a few different cheilostome bryozoan species (e.g. O'Dea \& Okamura 1999, 2000), has not been tested on Microporella.

Because ovicells are polymorphs thought to be structurally related to zooids, their size is hypothesized to be genetically constrained by zooid size in the same colony (Jackson \& Herrera Cubilla 2000). How much of ovicell and hence larval size is controlled by the average intra-colony zooid size; how much of it is influenced by external factors (e.g. physical conditions of the habitat); or what its relationship with fecundity is (usually a trade-off in solitary organisms), are, however, currently unknown. Shortterm experiments on cheilostome larval size (e.g. Marshall \& Keough 2004, Marshall \& Monro 2013) have focused on the drivers of selection for size and the effect of size on post-metamorphic performance, using invasive species commonly fouling piers (i.e. Bugula neritina, Watersipora subtorquata, Celleporaria sp.). For instance, an experimental reduction in maternal colony size resulted in smaller larvae (Marshall \& Keough 2004), while an increase in the number of biotic interactions is associated with larger ones (Allen et al. 2008, Marshall \& Keough 2009). Larger larvae can survive a longer period before settling, hence likely have a higher dispersal potential (Marshall \& Keough 2003). They also tend to develop into larger, more fecund colonies (Marshall \& Keough 2007, Muniz Dias \& Marshall 2010).

Previous investigations on cheilostome larval size variation were undertaken experimentally for single species (e.g. Marshall \& Keough 2004, 2007, 2009, Allen et al. 2008, Muniz Dias \& Marshall 2010, Marshall \& Monro 2013, Di Martino \& Liow 2021) or summarized from within entire communities (Jackson \& Herrera Cubilla 2000), but little is known of what, if 
Fig. 1. Scanning electron micrograph of a group of zooids of $\mathrm{Mi}$ croporella hyadesi (Jullien, 1888) (specimen ID: Natural History Museum London [NHMUK] 1990.10. 10.25, contemporary, Discovery Expedition Stn WS 249, Falkland Islands) from our database. Outlined in black is the perimeter of a zooid (number 16) and outlined in white is the perimeter of an ovicell (number 4) from which the areas of these polymorphs were estimated. The numbers indicate the zooids (black) and the ovicells (white) haphazardly selected and measured in this work. White asterisk: a deformed ovicell (i.e. teratology). Obvious malformations were avoided from measurements (see Section 2.1)

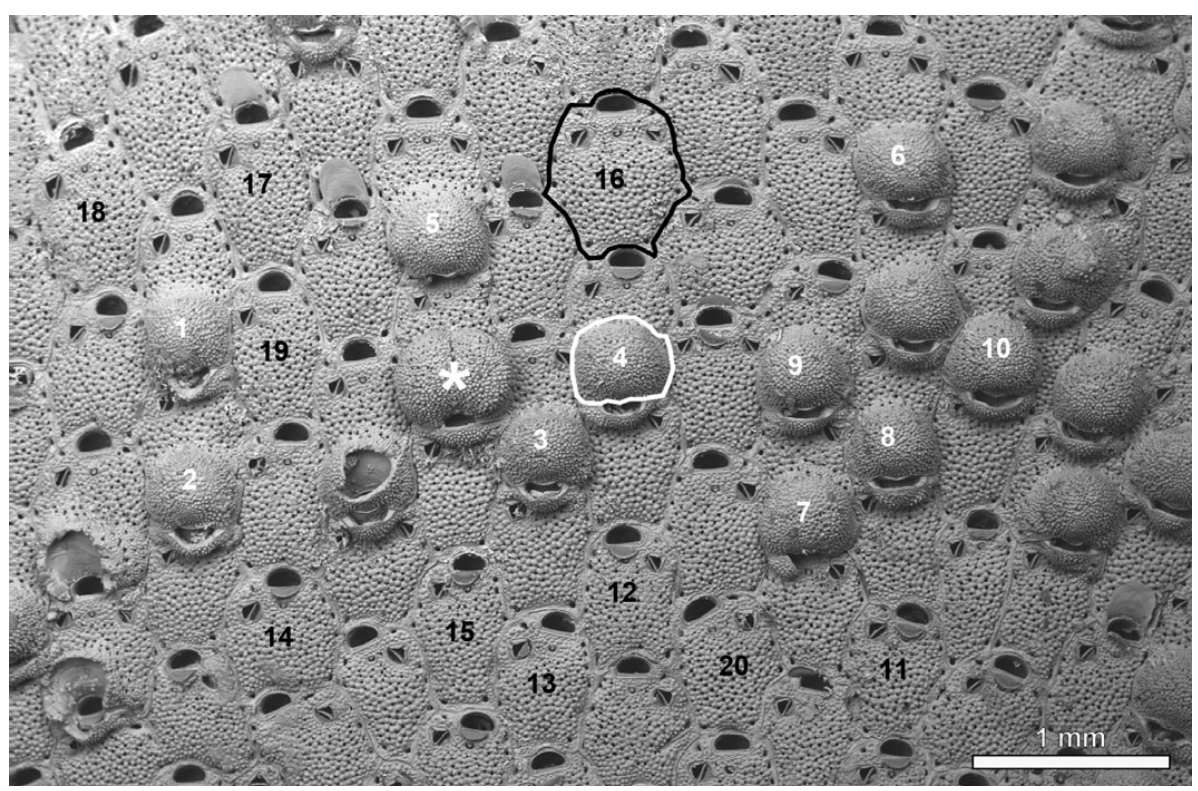

any constraints, might exist within lineages. Here we focus on a lineage, using multiple species of the same genus, Microporella, to ask the following questions: (1) Does zooid size explain most of the variation in larval size in contemporary species, or do trade-offs with density of ovicells (termed fecundity hereinafter for simplicity; see Section 2.1 for details and Section 4 for caveats) and/or environmental variation (temperature and/or nutrient levels) increase our ability to explain interspecific offspring/larval size variation? (2) We ask if the inferences we make for contemporary species hold for fossil species, using paleolatitude as a proxy for temperature. (3) Capitalizing on data from both fossil and contemporary species, we ask if both zooid and offspring/larval size increase over the millions of years of evolutionary history of this genus and if latitudinal shifts (a proxy for temperature changes), rather than Cope's rule, might explain evolutionary increases in size traits (i.e. an out-of-the-tropics scenario).

\section{MATERIALS AND METHODS}

\subsection{Data collection}

Our raw data consist of measurements of ovicell and zooid sizes (i.e. outline of areas as shown in Fig. 1) for all of the Microporella species (contemporary and fossil, described and undescribed) for which we could gather reliable measurements directly from scanning electron micrographs (SEMs). We use ovicell size as a proxy for offspring/larval size, following
Herrera \& Jackson (1996). Those authors demonstrated using contemporary populations of 2 species of ascophoran-grade cheilostome bryozoans that the size of ovicells is positively correlated with the size of brooded larvae (Kendall's coefficient of rank correlation tau $=0.52-0.89, \mathrm{p}=0.0051-0.0004)$.

We aimed to measure as many distinct species as possible to capture interspecific variation. For this study, we measured 58 contemporary and 27 fossil species (of which 13 are awaiting formal description) from SEMs (Fig. 1) using ImageJ (https://imagej.nih. gov/ij/). We measured 10 ovicells and 10 autozooids from a single colony, from 1 or multiple images where possible. In a few instances, measurements were taken from 2 or 3 colonies, with the constraint that they were from the same sampling site collected at the same time. Ovicells and autozooids were measured only if they were well defined, undamaged, free from distortion due to the substrate or teratology, and astogenetically mature (the first generation of zooids budded directly from the metamorphosed larva [i.e. ancestrula] are usually much smaller than later zooids). Fecundity was estimated as the ratio of ovicells to the total number of zooids (with and without ovicells) on the SEM (Fig. 1). Note that the SEMs from which we measured/counted the traits were taken previously for other diverse purposes and can be considered random with respect to the traits measured. For our main analyses, we use species means of zooid and ovicell area as a proxy for size (analyses involving length and width are shown in Figs. S1 \& S2 in Supplement 1 at www.int-res.com/ articles/suppl/m662p001_supp1.pdf). We assume that 
measurement error is negligible for area, as the precision of our repeated measurements is high (see Liow et al. 2017, Di Martino \& Liow 2021).

SEMs were supplemented with taxonomic identifications, geographical coordinates (latitude and longitude) and, for fossil species, geological age (see Datasets S1-S4 in Supplement 2 at www.int-res.com/ articles/suppl/m662p001_supp2.xlsx for specific information). The source of the geological age range in million years, if not explicitly expressed in the SEMs' metadata (see Supplement 2 for details of the original data sources), was taken from the International Chronostratigraphic Chart v. 2020/01 (https://stratigraphy.org/chart). The latitude of the fossil sampling sites was converted to paleolatitude using the Paleolatitude Calculator (www.paleolatitude.org/) with the default setting (van Hinsbergen et al. 2015).

Data for sea surface temperature (SST) and chlorophyll a (chl $a$, a proxy for ocean productivity or nutrient level for phytoplankton-feeders, like bryozoans) for the years 2002-2012 were downloaded from the NASA Earth Observations (NEO) website (MODISAqua Data 2020a,b). These data serve as a compro- mise between data availability for a relative temperature proxy we require and the fact that the majority of the colonies in our database were collected prior to 2002 (hence we did not use available SST and chl a data from later years). We matched the location of the monthly measured, $10 \mathrm{yr}$ average of SST and chl a with the $1 \times 1^{\circ}$ coordinates of the location where a given colony was found as an estimate of the (relative) environmental conditions it experienced.

Data on zooid size for 46 species from Liow \& Taylor (2019) were merged with the new data, adding 8 contemporary and 19 fossil species data from this study. Note that only 3 zooids per colony per species were measured in the 2019 study. For those species added from Liow \& Taylor (2019), we also measured ovicell size and fecundity where possible using the same SEMs or from different SEMs but part of the same specimen/colony. Fig. 2 shows the zooid and ovicell area variation of measured species singly and grouped by geological time and (paleo)latitude. We also show the variation averaged from 20 different colonies of $M$. agonistes spread over ca. 2 million yr measured in Liow et al. (2017) to suggest that much
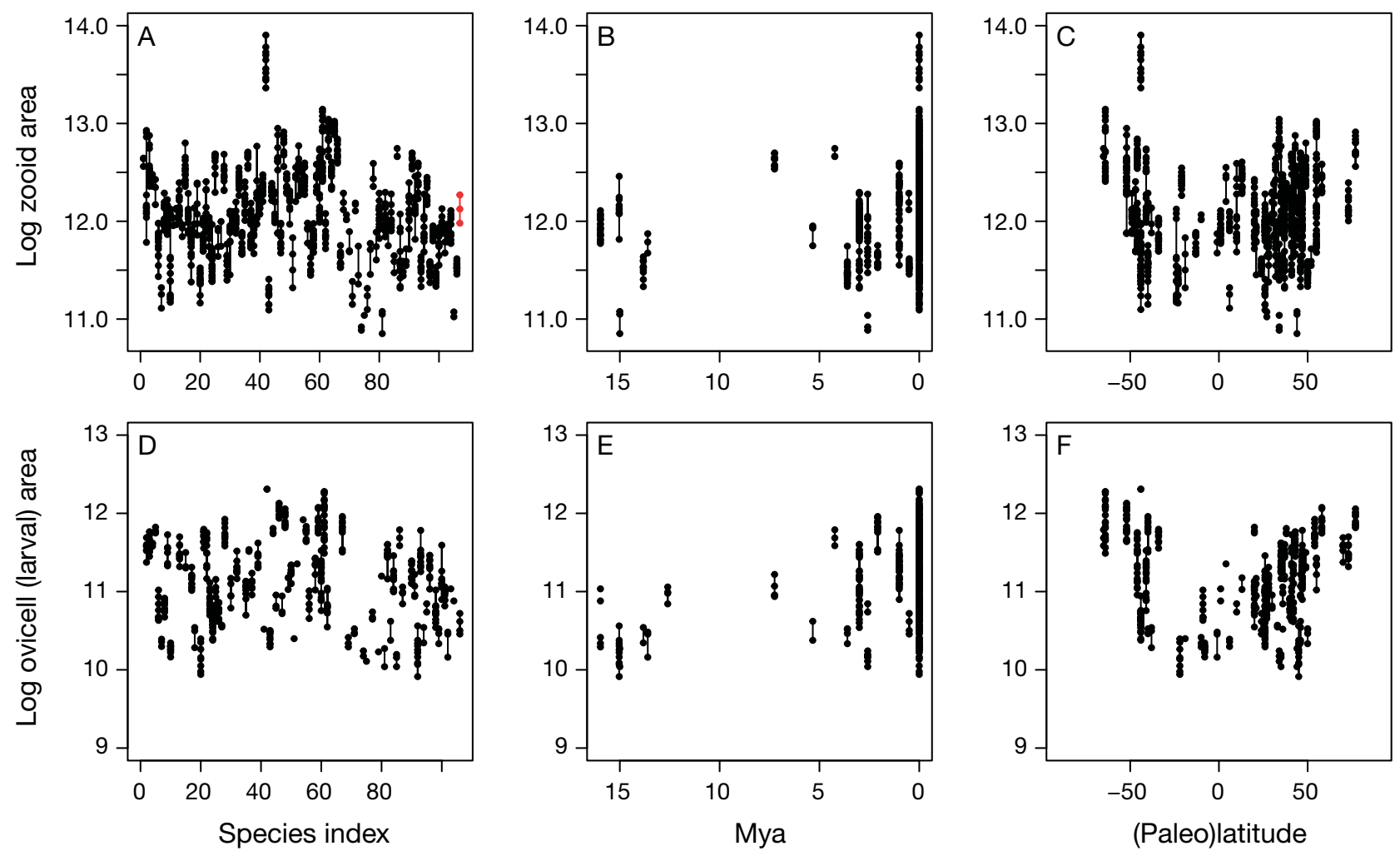

Fig. 2. Variation in zooid and larval size in Microporella. (A-C) The measured natural logged zooid areas (originally measured in $\mu^{2}$ ) for each species: (A) individual zooids measured in each species joined by vertical lines; red dots: mean and $95 \%$ CI distribution of 20 colonies of $M$. agonistes measured over 2 million yr from Liow et al. (2017); (B) species grouped by stratigraphic age (in millions of years ago, Mya); and (C) species grouped by (paleo)latitude in degrees. (D-F) The equivalent for natural logged ovicell (i.e. larval) areas: (D) the individual species; (E) grouped by age; and (F) grouped by (paleo)latitude 
of the within-species variation is likely captured with only 1 to a few colonies per species.

\subsection{Data analysis}

As the natural log of the ovicell area across our contemporary species is normally distributed (Shapiro test, $\mathrm{p}=0.39$ ), we used linear models for studying this trait. Our full model is

$$
O=b_{0}+b_{z} Z+b_{\mathrm{fec}} \mathrm{fec}+b_{\mathrm{SST}} \mathrm{SST}+b_{\mathrm{chl}} \mathrm{chl}
$$

where $O$ is mean natural log ovicell area, $Z$ is mean natural log autozooid area, fec is the mean ratio of ovicells to the total number of zooids for species, while SST and chl are the 10-yr averages of SST and chl a (see Section 2.1) where the specimens measured were collected. $b_{0}$ is the intercept for the model and $b_{\text {fec }}, b_{\mathrm{SST}}$ and $b_{\mathrm{chl}}$ are the slope for their respective terms. We compare 15 models (see Table 1) where we dropped or additively combined the 4 explanatory variables from Eq. (1). We are interested in which of these 15 models with their specific combination of explanatory variables will give the highest Akaike information criterion (AIC) weight (Burnham \& Anderson 2002) but are also interested in how much (additional) information each explanatory variable will give. The latter will be done by examining the standardized slopes and comparing the adjusted $\mathrm{R}^{2}$ values of the best model. We will also apply this general approach while using (paleo)latitude data and fossil species (see next paragraph). We also note that the variance inflation factors (VIFs) for all our analyses (see Code S1 in Supplement 1) are $<2$ and hence assume that there are no issues of multicollinearity among our included parameters (Zuur et al. 2010).

We do not have geographic location-specific estimates for SST for fossil colonies, hence we explore the suitability of latitude as a substitute for SST. Note that this serves as a rough approximation, as many additional factors (e.g. ocean currents, upwelling, stream confluence, turbidity) can influence the relationship between SST and latitude. We find that for the locations where our contemporary taxa are found, absolute latitude explains SST quite well $\left(\mathrm{R}^{2}=0.76\right.$, see Fig. S3 in Supplement 1), where a $0.43^{\circ} \mathrm{C}$ increase corresponds to $1^{\circ}$ latitude move towards the equator in our model. Natural log ovicell area across our fossil species is also normally distributed (Shapiro test, $\mathrm{p}=0.20$ ), hence we compare 7 linear models, where we used the potential explanatory variables log zooid area, fecundity, and absolute latitude (as a substitute for SST) in different additive combinations for the fossil colonies (see Table 2). We also analyzed fossil and contemporary species together (see Table 3), and separately, to quantify any differences in log zooid area, fecundity and latitude as explanatory variables for ovicell size given the 2 different classes of data (i.e. fossil and contemporary).

In addition to genetic constraints and environmental controls, evolutionary time may also point to how larval size may have evolved. As can be seen from Fig. 2, both larval and zooid size seem to have increased through geological time. We ask if the species within Microporella may follow Cope's rule, where descendant species have a higher chance of having larger zooids (for both zooids and ovicells) than their putative ancestors, following the 2 sampling procedures laid out in Liow \& Taylor (2019), in the absence of an independent phylogenetic hypothesis of the relationships among Microporella species. In the first procedure, any stratigraphically older species can give rise to any and multiple younger species, and the binomial probability of having a larger-sized descendant is calculated. In the second, a stratigraphically older species can give rise only to a single randomly selected descendant species. However, because there are many potential descendants to be picked for any older species, we repeat the analysis 1000 times to supply a distribution of the binomial probability of having a larger-sized descendant and compare this distribution to one where the size differences of pairs of species, regardless of their chronological age, are calculated (for more details, see Liow \& Taylor 2019). To ask if size differences are further explained by latitudinal shifts where there might be an overrepresentation of younger species that move north or southward from the equator (i.e. 'out-of-the-tropics' hypothesis) (Hunt \& Roy 2006, Jablonski et al. 2006), we also model zooid and ovicell size differences among putative ancestor-descendant pairs given the changes in geological time and latitudinal shifts. As the descendants must be randomly selected for each older species, we sample, without replacement, 1000 times from our data to create data subsets. These are then subject to 4 binomial models of size differences where a descendant is either larger (1) or not (0), with latitudinal shifts and time differences in different additive and multiplicative combinations (see Table 4). For the best model, we show the distribution (from the 1000 iterations) of the effect size and the distribution of the $p$-value for the variable in order to examine if the variable has any explanatory power.

All analyses were run in R v.3.6.1 (R Core Team 2019). Our new data, the data from Liow \& Taylor 
(2019) supplemented with new measurements, and the $M$. agonistes data from Liow et al. (2017) used in Fig. 2 are available in Supplement 2, and the R code for running all the above described analyses (and reproducing our plots and results) is available as Code S1 in Supplement 1.

\section{RESULTS}

\subsection{Ovicell/larval size in contemporary species}

Using the data subset of all the contemporary species for which we were able to measure ovicell area ( $\mathrm{N}=30$, each represented by at least 3 zooids, but with a median of 13 and maximum of 26), the best AIC-ranked linear model includes size and SST (Table 1). Here, an increase in 0.79 natural log units of zooid size gives a corresponding increase in 1 natural log unit of ovicell size, as does a decrease in SST by $-0.02^{\circ} \mathrm{C}$ (Table 1 , Fig. 3). Upon rescaling the variables, so they are mean-centered and scaled by $2 \mathrm{SD}$, the slope for zooid size is $0.84(\mathrm{SE}=0.14)$ and SST is -0.02 ( $\mathrm{SE}=0.1$ ) for the best model, suggesting that zooid size is more important than SST. The higher AIC-ranked models all include autozooid size; SST, where included, always contributes significantly; and all models that include autozooid size have adjusted $\mathrm{R}^{2}$ values that are at least 0.6. On the other hand, models that include fecundity and/or chl a are much less preferable based on AICc (Table 1). By including 14 more species with all the variables in the best model measured ( $\mathrm{N}=44$, Model i), the estimates and the adjusted $R^{2}$ value are very close to that estimated using $\mathrm{N}=30$ (Model 1). Substituting SST with latitude also yields similar estimates (Table 1). In summary, zooid size explains most of the variation in larval size in contemporary species as indicated by its slope estimates, but trade-off with the density of ovicells have shallow slopes and this variable does not even appear in the top AIC-ranked model. However, SST (but not chl a) increases our ability to explain interspecific ovicell variation, improving the adjusted $\mathrm{R}^{2}$ somewhat (Table 1, compare Models 1 and 3).

\subsection{Ovicell/larval size and zooid size in fossil species and all data combined}

Using the data subset with only fossil species and all covariates available $(\mathrm{N}=27)$, and absolute latitude as

Table 1. Models and estimates for ovicell (larval) area for contemporary species. Fifteen different linear additive models $(\mathrm{N}=$ 30 ) combining log area of zooids $(Z)$ and ovicells $(O)$, sea surface temperature (SST) (or (paleo)latitude, in the last row), fecundity (fec) and chlorophyll a (chl) are compared, using corrected Akaike information criterion (AICc), and their degrees of freedom (df), model weights and adjusted $\mathrm{R}^{2}$ are shown, together with the estimated size effect in the corresponding columns. Model i shows estimates for Model 1 when more data are used $(\mathrm{N}=44)$ and Model ii where absolute (paleo)latitude (lat) is substituted for SST. Bold: estimates that are significant at $p<0.05$. Models $i$ and ii are not compared with the models above (since the data used are different) and hence the $\mathrm{df}, \mathrm{AICc}$ and weight columns are labeled NA (not applicable)

\begin{tabular}{|c|c|c|c|c|c|c|c|c|c|c|}
\hline $\begin{array}{l}\text { Model } \\
\text { no. }\end{array}$ & Model & Intercept & $Z$ & fec & $\mathrm{SST}^{\mathrm{a}}$ & chl & df & $\mathrm{AICc}$ & Weight & Adj. $R^{2}$ \\
\hline 1 & $\sim Z+\mathrm{SST}$ & 1.172 & 0.845 & & -0.016 & & 4 & 21.135 & 0.433 & 0.687 \\
\hline 2 & $\sim Z+\mathrm{fec}+\mathrm{SST}$ & 2.172 & 0.771 & -0.219 & -0.018 & & 5 & 22.888 & 0.180 & 0.687 \\
\hline 3 & $\sim Z$ & -0.880 & 0.989 & & & & 3 & 23.348 & 0.143 & 0.645 \\
\hline 4 & $O \sim Z+\mathrm{SST}+\mathrm{chl}$ & 1.165 & 0.845 & & -0.016 & 0.003 & 5 & 24.033 & 0.102 & 0.675 \\
\hline 5 & $\sim Z+\mathrm{chl}$ & -0.849 & 0.983 & & & 0.050 & 4 & 25.720 & 0.044 & 0.635 \\
\hline 6 & $\sim Z+$ fec & -0.450 & 0.957 & -0.117 & & & 4 & 25.740 & 0.043 & 0.635 \\
\hline 7 & $\sim Z+\mathrm{fec}+\mathrm{SST}+\mathrm{chl}$ & 2.221 & 0.765 & -0.244 & -0.017 & 0.034 & 6 & 25.888 & 0.040 & 0.676 \\
\hline 8 & $\sim Z+\mathrm{fec}+\mathrm{chl}$ & -0.176 & 0.931 & -0.178 & & 0.075 & 5 & 28.025 & 0.014 & 0.629 \\
\hline 9 & $\sim \mathrm{fec}+\mathrm{SST}$ & 12.062 & & -0.695 & -0.035 & & 4 & 39.018 & 0.000 & 0.432 \\
\hline 10 & $\sim \mathrm{fec}+\mathrm{SST}+\mathrm{chl}$ & 11.989 & & -0.746 & -0.034 & 0.082 & 5 & 41.456 & 0.000 & 0.419 \\
\hline 11 & $\sim \mathrm{SST}$ & 11.848 & & & -0.036 & & 3 & 43.357 & 0.000 & 0.308 \\
\hline 12 & $\sim \mathrm{SST}+\mathrm{chl}$ & 11.869 & & & -0.037 & -0.020 & 4 & 46.011 & 0.000 & 0.282 \\
\hline 13 & $\sim \mathrm{fec}$ & 11.433 & & -0.729 & & & 3 & 50.432 & 0.000 & 0.123 \\
\hline 14 & $\sim \mathrm{fec}+\mathrm{chl}$ & 11.318 & & -0.855 & & 0.209 & 4 & 51.022 & 0.000 & 0.152 \\
\hline 15 & $\sim \mathrm{chl}$ & 11.117 & & & & 0.103 & 3 & 54.982 & 0.000 & 0.020 \\
\hline $\mathrm{i}$ & $\sim Z+\operatorname{SST}(\mathrm{N}=44)$ & 1.915 & 0.793 & & -0.020 & & NA & NA & NA & 0.668 \\
\hline ii & $\sim Z+$ lat $(\mathrm{N}=44)$ & 1.152 & 0.802 & & 0.008 & & NA & NA & NA & 0.652 \\
\hline
\end{tabular}



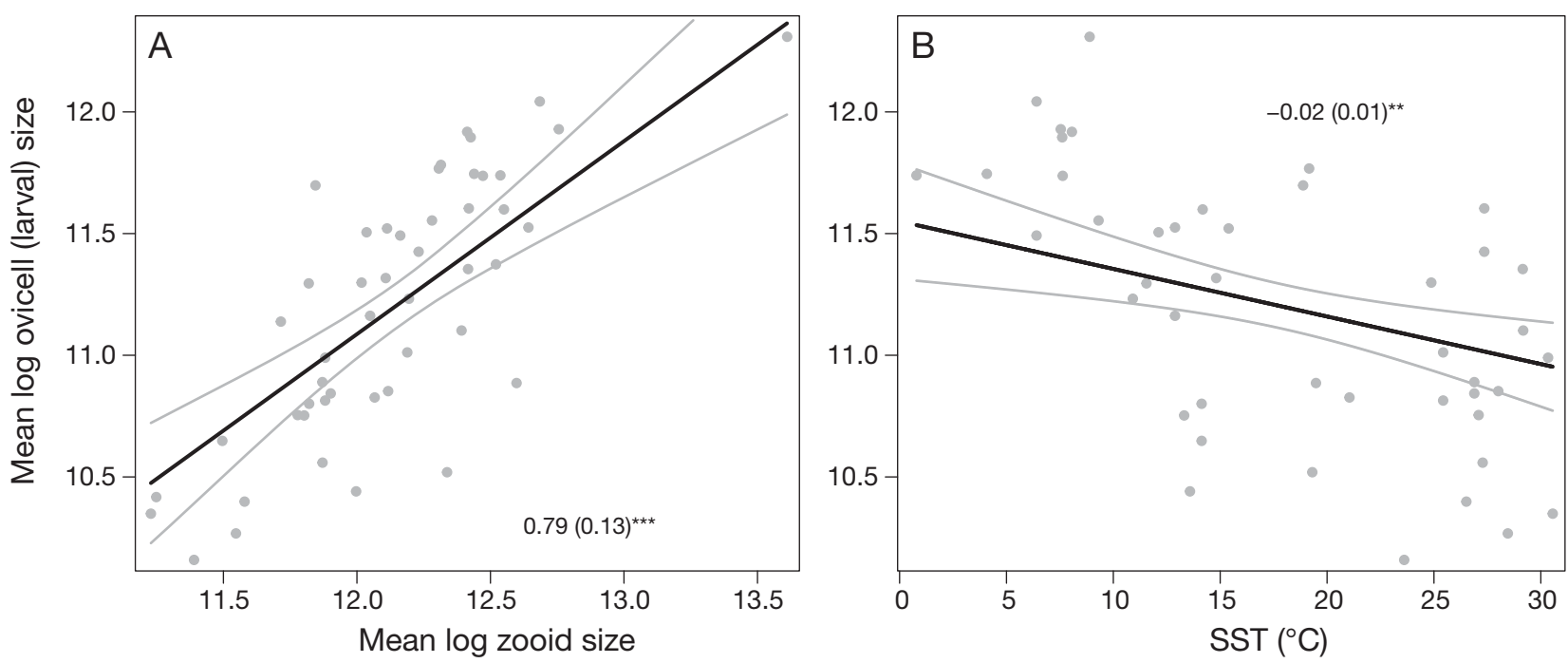

Fig. 3. Best model for ovicell (larval) size. Plots show species averages (grey dots) for ovicell and zooid sizes (areas, natural logged, originally measured in $\mu^{2}$ ) for contemporary species. Sea surface temperature (SST) values are the 10-yr means from the closest geographic coordinates (see Section 2.1). Black solid lines: model fits for each of the explanatory variables; grey lines: 95\% CI (see Table 1). Numbers within each plot: effect size and standard error (in parentheses) for the dependent variable; ${ }^{* *} \mathrm{p}<0.01 ;{ }^{* * *} \mathrm{p}<0.001$

a proxy for SST, the best AIC-ranked linear multivariate model includes only natural log zooid size (Table 2), where an increase in 0.75 natural log units of zooid size gives a corresponding increase in 1 natural log unit of ovicell size. Upon rescaling the variables, so they are mean-centered and scaled by $2 \mathrm{SD}$, the slope for zooid size is $0.73(\mathrm{SE}=0.12)$ and latitude is 0.20 ( $\mathrm{SE}=1.2$ ) for the best model, suggesting that zooid size is more important than latitude. In the lower ranked models, fecundity and latitude had little to no explanatory power for ovicell size (Table 2). By including 7 more species with all the variables in the best model measured $(\mathrm{N}=34)$, the estimates and the $\mathrm{R}^{2}$ are close to that estimated using $\mathrm{N}=27$ (Table 2). Combining fossil and contemporary species and fitting the same 7 models we applied to the fossil-only dataset, we find that the model with log zooid size and latitude still ranks best (Table 3), with fecundity supplying little additional information. By fitting the model separately to fossil, contemporary and all data, we see that the slope of the relationship between latitude and size is slightly steeper for the relationship between ovicell size and latitude (Fig. 4), but note that without including zooid area as an explanatory vari-

Table 2. Models and estimates for ovicell (larval) area for fossil species. Seven different linear additive models $(\mathrm{N}=27) \mathrm{com}-$ bining log zooid area $(Z)$, absolute paleolatitude (lat) and fecundity (fec) are compared, using corrected Akaike information criterion (AICc), and their degrees of freedom (df), model weights and adjusted $\mathrm{R}^{2}$ are shown, together with the estimated effect size in the corresponding columns. Model i shows estimates for Model 1 when more data are used $(\mathrm{N}=34)$. As Model i is not compared with the models above, the df, AICc and weight columns are labeled NA (not applicable). Bold: estimates that are significant at $\mathrm{p}<0.05$

\begin{tabular}{|c|c|c|c|c|c|c|c|c|c|}
\hline $\begin{array}{l}\text { Model } \\
\text { no. }\end{array}$ & Model & Intercept & $Z$ & fec & lat & df & $\mathrm{AICc}$ & Weight & Adj. $\mathrm{R}^{2}$ \\
\hline 1 & $\sim Z$ + lat & 2.205 & 0.706 & & 0.005 & 4 & -4.917 & 0.404 & 0.630 \\
\hline 2 & $\sim Z$ & 1.736 & 0.763 & & & 4 & -6.328 & 0.395 & 0.606 \\
\hline 3 & $\sim Z+$ fec + lat & 2.513 & 0.682 & -0.130 & 0.006 & 5 & -4.779 & 0.102 & 0.618 \\
\hline 4 & $\sim Z+$ fec & 1.732 & 0.763 & 0.002 & & 5 & -6.328 & 0.099 & 0.589 \\
\hline 5 & $\sim \mathrm{fec}+$ lat & 10.538 & & -0.642 & 0.013 & 4 & -15.184 & 0.000 & 0.209 \\
\hline 6 & lat & 10.390 & & & 0.011 & 3 & -16.908 & 0.000 & 0.137 \\
\hline 7 & $\sim \mathrm{fec}$ & 10.949 & & -0.468 & & 3 & -18.666 & 0.000 & 0.017 \\
\hline $\mathrm{i}$ & $\sim Z+$ lat $(\mathrm{N}=34)$ & 2.488 & 0.688 & & 0.006 & NA & NA & NA & 0.494 \\
\hline
\end{tabular}


Table 3. Models and estimates for ovicell (larval) area for fossil and contemporary species combined. Seven different linear additive models ( $\mathrm{N}=63$ ) combining log zooid area $(Z)$, absolute (paleo)latitude (lat) and fecundity (fec) are compared, using corrected Akaike information criterion (AICc), and their degrees of freedom (df), model weights and adjusted $\mathrm{R}^{2}$ are shown, together with the estimated effect size in the corresponding columns. Model i shows estimates for Model 1 when more data are used $(\mathrm{N}=78$ ). As Model $\mathrm{i}$ is not compared with the models above, the df, AICc and weight columns are labeled NA (not applicable). Bold: estimates that are significant at $\mathrm{p}<0.05$

\begin{tabular}{|c|c|c|c|c|c|c|c|c|c|}
\hline $\begin{array}{l}\text { Model } \\
\text { no. }\end{array}$ & Model & Intercept & $Z$ & fec & lat & $\mathrm{df}$ & $\mathrm{AICc}$ & Weight & Adj. $\mathrm{R}^{2}$ \\
\hline 1 & $\sim Z$ + lat & 0.825 & 0.828 & & 0.006 & 4 & 39.401 & 0.603 & 0.680 \\
\hline 2 & $\sim Z+$ fec + lat & 1.166 & 0.802 & -0.144 & 0.007 & 5 & 40.833 & 0.295 & 0.679 \\
\hline 3 & $\sim Z$ & 0.144 & 0.904 & & & 3 & 43.550 & 0.076 & 0.651 \\
\hline 4 & $\sim Z+$ fec & 0.286 & 0.894 & -0.070 & NA & 4 & 45.631 & 0.027 & 0.646 \\
\hline 5 & $\sim \mathrm{fec}+$ lat & 10.638 & NA & -0.564 & 0.016 & 4 & 92.188 & 0.000 & 0.260 \\
\hline 6 & lat & 10.482 & NA & NA & 0.015 & 3 & 96.322 & 0.000 & 0.193 \\
\hline 7 & $\sim \mathrm{fec}$ & 11.188 & NA & -0.494 & NA & 3 & 107.064 & 0.000 & 0.044 \\
\hline i & $\sim Z+$ lat $(\mathrm{N}=78)$ & 1.265 & 0.792 & & 0.007 & 3 & NA & NA & 0.621 \\
\hline
\end{tabular}
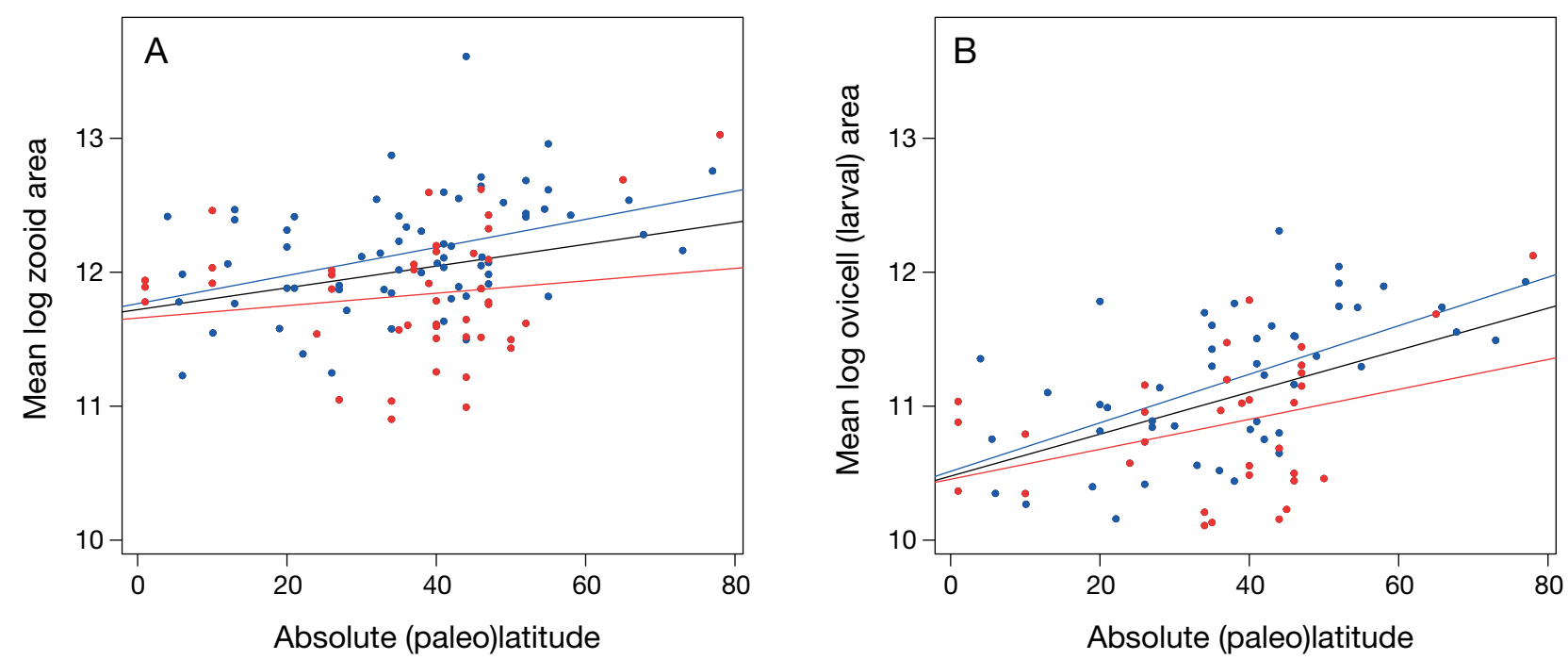

Fig. 4. Relationship between size and absolute (paleo)latitude. (A) Data and fit for a simple univariate linear model for zooid area and absolute (paleo)latitude; (B) the same but for ovicell area (both originally measured in $\mu^{2}$ ). Red points: data from the fossil record (regardless of age); blue points: from contemporary material. Black lines: fits for all the data; blue lines: for contemporary; red lines: for fossil only. Zooid area is positively related to latitude for contemporary species $($ slope $=0.01$, $\mathrm{SE}=$ $0.003, p=0.0008)$ but not for fossil ones $(0.004,0.005,0.3)$. Ovicell area is positively related to latitude for both contemporary species $\left(0.02,0.0034,1.62 \times 10^{-5}\right)$ and fossil ones $(0.01,0.005,0.0325)$

able, the amount of variation explained is low (see Table 3). In summary, the qualitative inferences we make for contemporary species hold for fossil species using paleolatitude as a proxy for temperature.

\subsection{Ovicell/larval size and zooid size through time (Cope's rule and 'out-of-the-tropics' hypothesis)}

The binomial probability of a descendant having larger zooids is 0.67 (95\% CI 0.66-0.69, putative ancestral-descendant pairs: $\mathrm{N}=3714$ ), while that for ovicells is 0.66 (95\% CI 0.64-0.68, putative ancestraldescendant pairs: $\mathrm{N}=2164$ ), using our first approach for tackling unknown ancestral-descendant relationships (Fig. 5A,B). Likewise, in the second approach, the binomial probability of the descendant having both larger zooids and ovicells is clearly larger than randomized pairs of species (Fig. 5C,D). Fitting 4 models (Table 4) with randomly selected ancestraldescendant pairs, we find that the model best describing size differences is one that involves only latitudinal shifts, i.e. the amount of time that has passed does not matter. The distribution of the effect of latitudinal 

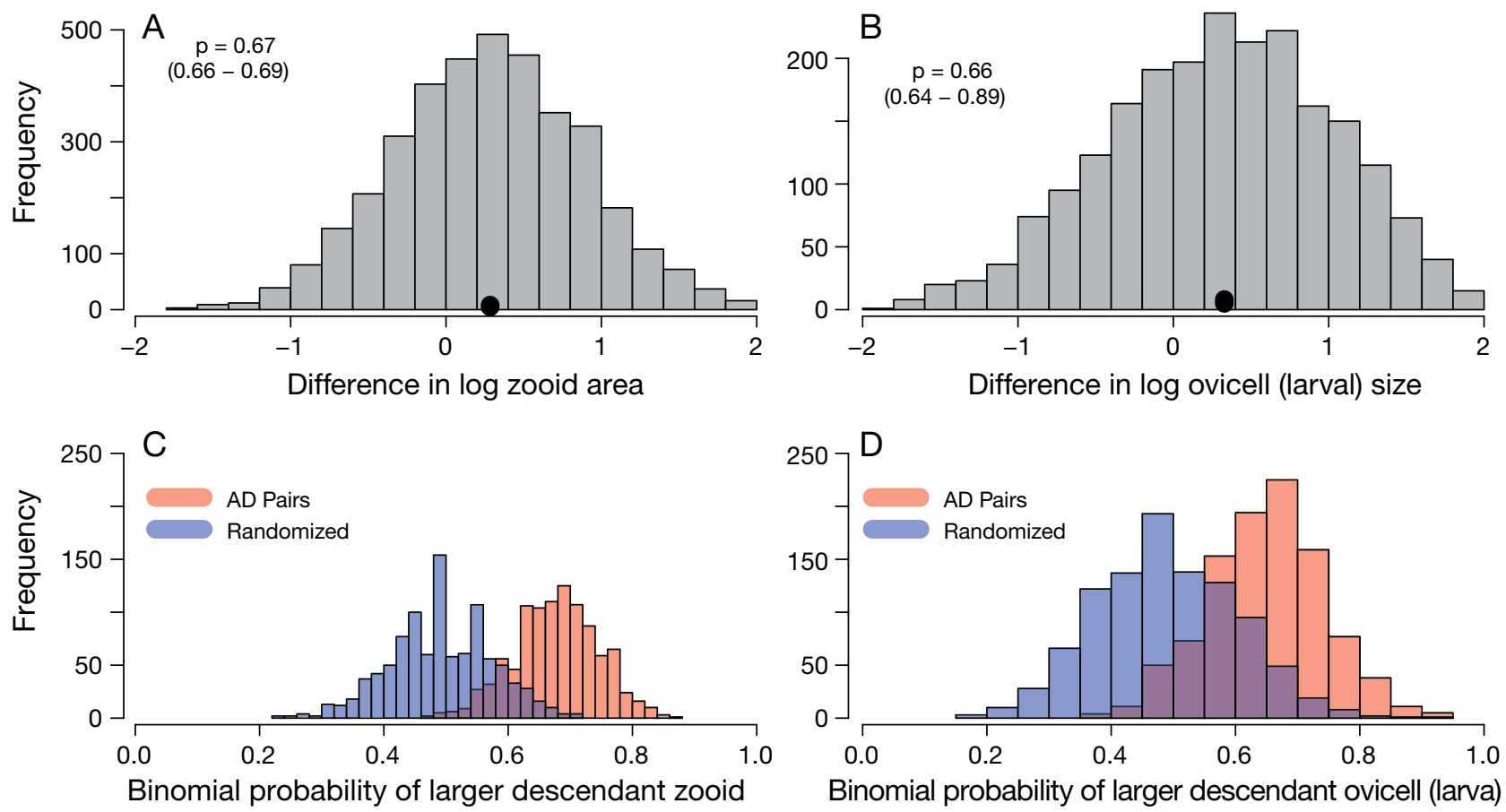

Fig. 5. Cope's rule for zooid and ovicell area in Microporella. (A,B) Distribution of the differences between all plausible ancestor-descendant pairs for (A) log zooid size and (B) log ovicell size. The binomial probability of descendants being larger is shown on the left of each plot, with $95 \%$ CI in parentheses. Black solid circles indicate the mean of the distributions, both of which are greater than 0. (C,D) Distribution of binomial probabilities of descendant being larger in ancestor-descendant pairs (AD pairs) which are repeatedly drawn (red), compared with species pairs repeatedly drawn, but disregarding temporal order (blue), for (C) zooid and (D) ovicell

Table 4. Models for latitudinal shifts in ancestor-descendant pairs. Four models were run 100 times (since ancestordescendant pairs must be selected), using the magnitude of latitudinal differences (shift) and the time that has passed (time.diff). No. times: how many times of the 1000 runs the model was ranked top; model weight: the median model weight when that model is selected as top

\begin{tabular}{|lccc|}
\hline $\begin{array}{c}\text { Model } \\
\text { no. }\end{array}$ & Models & No. times & $\begin{array}{c}\text { Model } \\
\text { weight }\end{array}$ \\
\hline 1 & $\sim$ shift & 594 & 0.473 \\
2 & $\sim$ shift+time.diff & 18 & 0.437 \\
3 & $\sim$ time.diff & 357 & 0.443 \\
4 & $\sim$ shift $\times$ time.diff & 76 & 0.517 \\
\hline
\end{tabular}

shifts is close to zero (Fig. 6A) in repeated runs of the best model (in Table 4), and the distribution of its pvalue clearly much larger than 0.05 (Fig. 6B), indicating that latitudinal shifts do not explain much beyond what is already described by categorical, putative ancestral-descendant pairs (i.e. the dependent variable in these models). In summary, Cope's rule seems sufficient for explaining the changes in ancestordescendent size difference, i.e. there is no need to invoke an 'out-of-the-tropics' scenario.

\section{DISCUSSION}

Little is currently known about how offspring size varies within lineages and over macroevolutionary timescales, much less what constrains or drives the evolution of larval size in marine invertebrates (e.g. Marshall et al. 2018a). Our study system offers unique insights into the evolution of offspring size in deep time, as it is possible to measure offspring size in multiple contemporary and fossil congeneric species within a well-defined evolutionary lineage.

As already hinted upon in Jackson \& Herrera $\mathrm{Cu}-$ billa (2000) and quantified here for Microporella, it is clear that ovicell, and hence larval size, is constrained by zooid size, although the underlying mechanisms of this allometric relationship remain to be investigated. We surprisingly did not find a trade-off between offspring size and number. This could be because our data are interspecific rather than intraspecific, suggesting that the differences in offspring size and number among species might be regulated by different factors than energy balance (e.g. Marshall et al. 2018b). The patterns we found using SST and latitude give support to previous less extensive studies on zooid size variation, where larger zooids are thought 

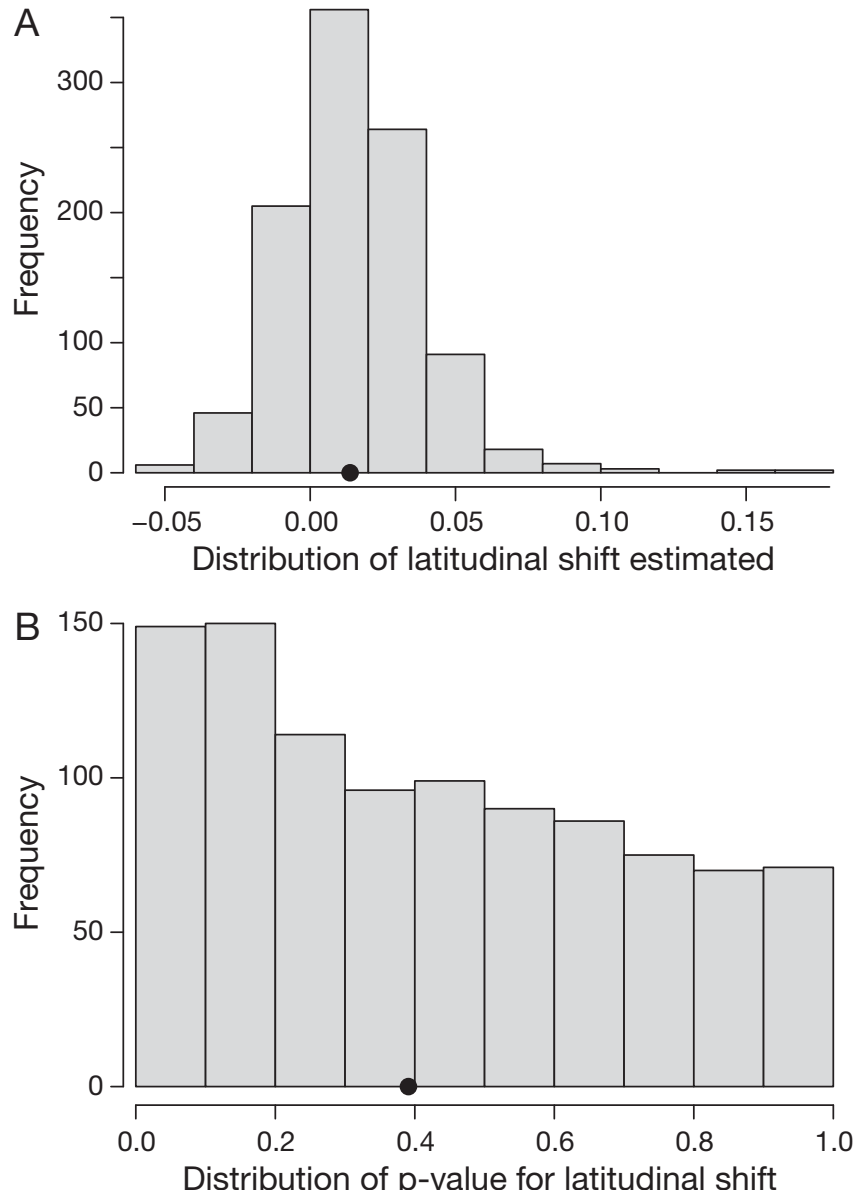

Fig. 6. Testing the out-of-the-tropics hypothesis. (A) Distribution of the estimated effect size of latitudinal shift in repeatedly sampled putative ancestor-descendant pairs from the first ( shift) model in Table 4. (B) Distribution of the pvalue of these effect sizes. Black dots in each panel are means

to be associated with higher latitudes (Kukliński \& Taylor 2008) and colder waters (e.g. Ryland 1963, Menon 1972, Okamura \& Bishop 1988, Hunter \& Hughes 1994, O'Dea \& Okamura 1999). Our results also confirm body size-codified generalizations, i.e. Bergmann's rule (e.g. Meiri \& Dayan 2003) - the tendency for organisms living in higher latitudes to be larger than their counterparts in lower latitudes and Atkinson's temperature-size rule (Atkinson 1994) - the favoring of larger body sizes in cooler environments - for ovicell/larval size in addition to zooid size for a colonial organism whose colony size is indeterminate. That said, it is likely that the mechanisms for larger size in colder waters in such colonial organisms are likely different from those of solitary organisms, often couched as a consequence of the product of growth rate and development rate (e.g. Forster \& Hirst 2012). Bryozoan temperature-size re- sponse may be explained with oxygen limitation, where lower temperatures can hold higher concentrations of oxygen, all things being equal (e.g. O'Dea \& Okamura 1999, O'Dea 2005).

In a handful of cheilostomes (Flustra, Conopeum, Celleporella), zooid size is found to be strongly influenced by ambient water temperature but independent of food levels (e.g. Hunter \& Hughes 1994, O'Dea \& Okamura 1999, 2000, O'Dea 2005) as we also show here, with chl a level as a proxy for nutrient levels. In Electra pilosa, there is an optimal food concentration for zooid size (Hageman et al. 2009). In contrast, Jackson \& Herrera Cubilla (2000), studying the differences in zooid and ovicell size variation at community level between the 2 sides of the Isthmus of Panama, suggest that larger zooids and ovicells are generated in oligotrophic but stable environments. In other words, size has a complex relationship with nutrient levels and among species, as in our study, the effect of varying nutrient levels may be masked by genetic constraints, which are more dominant than phenotypic responses to ecological effects.

Our results contradict those found in marine invertebrates with non-feeding larvae but mostly based on non-bryozoan taxa, in which larger offspring are associated with lower level of nutrients (Marshall et al. 2012). It remains possible that temperature effects swamp any nutrient signals in our data (see also Pettersen et al. 2019, Álvarez-Noriega et al. 2020, Marshall et al. 2020). In addition, we do not detect any differences in offspring size between southern and northern hemispheres ( $t$-test for contemporary species, Northern hemisphere: $N=45$, Southern: $N=21$, $t=-0.14,95 \% \mathrm{CI}:-0.63$ to $0.57, \mathrm{p}=0.82$ ), as is apparent for other marine invertebrates (from the phyla Annellida, Echinodermata, Mollusca) with non-feeding larvae (Marshall et al. 2012).

Microporella module size, regardless of whether zooids or larvae (ovicells) are measured, conform to Cope's rule (e.g. Heim et al. 2015) - the increase of the body size of evolutionary lineages through geological time-as previously observed for zooids across different cheilostome bryozoan species (Liow \& Taylor 2019). The probability of a descendant having larger ovicells or zooids than its putative ancestor is higher than a null hypothesis of no size difference, with this size difference little explained by a latitudinal shift happening over time, casting doubt on an out-of-the-tropics scenario when interpreted in the light of a latitudinal relationship of module size distribution (Figs. $2 \& 4$ ). It is somewhat paradoxical that there is a clear trend in zooid size increase which is simultaneously controlled by environmental condi- 
tions (temperature, Fig. 2), yet whose effect is unclear over time (Fig. 4). The evolutionary push and pull between time (i.e. survival and speciation in time, given biotic interactions and genetic constraints) and physical conditions hence call for further study.

A number of caveats need to be considered. Our module size and fecundity dataset, although being the most comprehensive in relation to the number of Microporella species measured, includes two-thirds of the species known to date. The species missing are usually described in early publications before SEM imaging was available, rarely collected thereafter, and with their type specimens currently unavailable to us. However, we believe that the subset of species included in this study are randomly distributed with regards to our traits of interest, which are ovicell and zooid sizes. Measurements error may account for variation in size traits, but we are confident that the repeatability of our zooid measurements is highly accurate, as demonstrated earlier (see Liow et al. 2017, Di Martino \& Liow 2021). We used the number of ovicells as an estimate for fecundity, as it is common practice in studies based on cheilostome bryozoans (see Yagunova \& Ostrovsky 2010 and references therein); however, this is an apparent, instantaneous fecundity which can either be an over- or an underestimation of the (relative) life-time fecundity of the colony. Not all ovicells will produce successful larvae that are recruited to the next generation, and perhaps some ovicells can be re-used, although this has never been observed for Microporella. Lastly, pending an independent and robust Microporella phylogeny that includes both fossil and contemporary species (see Orr et al. 2018), the relationship between ancestral and descendant species could only be speculated using chronological age as information.

\section{CONCLUSIONS}

Offspring/larval size is likely genetically constrained by the characteristic size of non-reproductive modules but also a consequence of the external environment a species experiences. However, the imprint of evolution, where ancestral species tend to give rise to larger module-size descendants, cannot simply be explained by a tendency for younger species to have moved to higher latitudes. Offspring investment (in terms of offspring size) of these modular organisms does not seem to trade off with offspring number, but is instead a consequence of genetic constraints and environmental temperatures.
Our study illustrates how capitalizing on among species variation in both contemporary organisms and their fossil counterpart can give insights that are otherwise difficult to obtain, but also how using model systems at different scales (i.e. single species, communities, species within a lineage as we have done here) can reveal different aspects and the complexity of the variation.

Acknowledgements. We thank Paul D. Taylor for inspiring this work. We are also grateful to Paul D. Taylor, M. H. Dick, L. Ramalho, K. Zágoršek, J. E. Winston, A. Rosso, J.-G. Harmelin, and B. Figuerola who kindly made available their Microporella SEM images. E.D.M. has received funding from the European Research Council (ERC) under the European Union's Horizon 2020 research and innovation program (grant agreement No. 724324 to L.H.L.). D. J. Marshall, S. Hageman, and an anonymous reviewer provided useful comments that greatly improved the originally submitted manuscript.

\section{LITERATURE CITED}

Allen RM, Buckley YM, Marshall DJ (2008) Offspring size plasticity in response to intraspecific competition: an adaptive maternal effect across life-history stages. Am Nat 171:225-237

Álvarez-Noriega M, Burgess SC, Byers JE, Pringle JM, Wares JP, Marshall DJ (2020) Global biogeography of marine dispersal potential. Nat Ecol Evol 4:1196-1203

*Atkinson D (1994) Temperature and organism size-a biological law for ectotherms? Adv Ecol Res 25:1-58

Bock P (2020) Microporella Hincks, 1877. The Bryozoa home page. www.bryozoa.net/cheilostomata/microporellidae/ microporella.html (accessed 10 Oct 2020)

Burnham KP, Anderson DR (2002) Model selection and multimodel inference: a practical information-theoretic approach, 2nd edn. Springer, New York, NY

d'Hondt JL (1977) Valeur systématique de la structure larvaire et des particularités de la morphogenèse post-larvaire chez les Bryozoaires Gymnolaemates. Gegenbaurs Morphol Jahrb 123:463-483

* Dick MH, Grischenko AV, Mawatari SF (2005) Intertidal Bryozoa (Cheilostomata) of Ketchikan, Alaska. J Nat Hist 39:3687-3784

Di Martino E, Liow LH (2021) Trait-fitness associations do not predict within-species phenotypic evolution over 2 million years. Proc R Soc B 288:20202047

Figuerola B, Gordon DP, Cristobo J (2018) New deep Cheilostomata (Bryozoa) species from the Southwestern Atlantic: shedding light in the dark. Zootaxa 4375:211-249

*Forster J, Hirst AG (2012) The temperature-size rule emerges from ontogenetic differences between growth and development rates. Funct Ecol 26:483-492

*Hageman SJ, Needham LL, Todd CD (2009) Threshold effects of food concentration on the skeletal morphology of the bryozoan Electra pilosa (Linnaeus, 1767). Lethaia 42:438-451

* Heim NA, Knope ML, Schaal EK, Wang SC, Payne JL (2015) Cope's rule in the evolution of marine animals. Science $347: 867-870$ 
Herrera A, Jackson JBC (1996) Life history variation among 'dominant' encrusting cheilostomate Bryozoa. In: Gordon DP, Smith AM, Grant-Mackie JA (eds) Bryozoans in space and time. NIWA, Wellington, p 117-123

Hiebert LS, Simpson C, Tiozzo S (2020) Coloniality, clonality, and modularity in animals: the elephant in the room. J Exp Zool B (in press), doi:10.1002/jez.b.22944

Hunt G, Roy K (2006) Climate change, body size evolution, and Cope's rule in deep-sea ostracodes. Proc Natl Acad Sci USA 103:1347-1352

Hunter E, Hughes R (1994) The influence of temperature, food ration and genotype on zooid size in Celleporella hyalina (L.). In: Hayward PJ, Ryland JS, Taylor PD (eds) Biology and palaeobiology of bryozoans. Olsen \& Olsen, Fredensborg, p 83-86

Jablonski D, Lutz RA (1983) Larval ecology of marine benthic invertebrates: paleobiological implications. Biol Rev Camb Philos Soc 58:21-89

Jablonski D, Roy K, Valentine JW (2006) Out of the tropics: evolutionary dynamics of the latitudinal diversity gradient. Science 314:102-106

* Jackson JBC (1977) Competition on marine hard substrata: the adaptive significance of solitary and colonial strategies. Am Nat 111:743-767

Jackson JBC (1985) Distribution and ecology of clonal and aclonal marine invertebrates. In: Jackson JBC, Buss LW, Cook RE (eds) Population biology and evolution of clonal organisms. Yale University Press, New Haven, CT, p 297-355

Jackson JBC, Herrera Cubilla A (2000) Adaptation and constraint as determinants of zooid and ovicell size among encrusting ascophoran cheilostome Bryozoa from opposite sides of the Isthmus of Panama. In: Herrera Cubilla A, Jackson JBC (eds) Proc 11th Int Bryozool Assoc Conf. Smithsonian Tropical Research Institute, Balboa, p 249-258

Jeffery CH, Emlet RB (2003) Macroevolutionary consequences of developmental mode in temnopleurid echinoids from the Tertiary of southern Australia. Evolution 57:1031-1048

Kukliński P, Taylor PD (2008) Are bryozoans adapted for living in the Arctic? In: Hageman SJ, Key MMJ Jr, Winston JE (eds) Proc 14th Int Bryozool Assoc Conf, Boone, NC. Virginia Museum of Natural History, Martinsville, VA, p 101-110

Liow LH, Taylor PD (2019) Cope's rule in a modular organism: directional evolution without an overarching macroevolutionary trend. Evolution 73:1863-1872

Liow LH, Di Martino E, Krzeminska M, Ramsfjell M, Rust S, Taylor PD, Voje KL (2017) Relative size predicts competitive outcome through 2 million years. Ecol Lett 20:981-988

KLiow LH, Reitan T, Voje KL, Taylor PD, Di Martino E (2019) Size, weapons, and armor as predictors of competitive outcomes in fossil and contemporary marine communities. Ecol Monogr 89:e01354

Marshall DJ, Keough MJ (2003) Variation in the dispersal potential of non-feeding invertebrate larvae: the desperate larva hypothesis and larval size. Mar Ecol Prog Ser 255:145-153

Marshall DJ, Keough MJ (2004) When the going gets rough: effect of maternal size manipulation on larval quality. Mar Ecol Prog Ser 272:301-305

Marshall DJ, Keough MJ (2007) The evolutionary ecology of offspring size in marine invertebrates. Adv Mar Biol 53: $1-60$
Marshall DJ, Keough MJ (2008) The relationship between offspring size and performance in the sea. Am Nat 171: 214-224

Marshall DJ, Keough MJ (2009) Does interspecific competition affect offspring provisioning? Ecology 90:487-495

Marshall DJ, Monro K (2013) Interspecific competition alters nonlinear selection on offspring size in the field. Evolution 67:328-337

* Marshall DJ, Krug PJ, Kupriyanova EK, Byrne M, Emlet RB (2012) The biogeography of marine invertebrate life histories. Annu Rev Ecol Evol Syst 43:97-114

* Marshall DJ, Pettersen AK, Cameron H (2018a) A global synthesis of offspring size variation, its co-evolutionary causes and consequences. Funct Ecol 32:1436-1446

Marshall DJ, McAlister J, Reitzel A (2018b) Evolutionary ecology of parental investment and larval diversity. In: Carrier TJ, Reitzel AM, Heyland A (eds) Evolutionary ecology of marine invertebrate larvae. Oxford University Press, New York, NY, p 34-49

* Marshall DJ, Pettersen AK, Bode M, White CR (2020) Developmental cost theory predicts thermal environment and vulnerability to global warming. Nat Ecol Evol 4: 406-411

Martins MJF, Puckett TM, Lockwood R, Swaddle JP, Hunt G (2018) High male sexual investment as a driver of extinction in fossil ostracods. Nature 556:366-369

* Meiri S, Dayan T (2003) On the validity of Bergmann's rule. J Biogeogr 30:331-351

Menon NR (1972) Heat tolerance, growth and regeneration in three North Sea bryozoans exposed to different constant temperatures. Mar Biol 15:1-11

MODIS-Aqua Data (2020a) Dataset for sea surface temperature (1 month-AQUA/MODIS) (https://neo.sci.gsfc.nasa. gov/view.php?data setId=MYD28M) Ocean Biology Processing Group, Ocean Ecology Laboratory, NASA Goddard Space Flight Center (accessed 4 September 2020)

MODIS-Aqua Data (2020b) Dataset for chlorophyll concentration (1 month - AQUA/MODIS) (https://neo.sci.gsfc. nasa.gov/view.php?datasetId=MY1DMM_CHLORA) Ocean Biology Processing Group, Ocean Ecology Laboratory, NASA Goddard Space Flight Center (accessed 4 September 2020)

Muniz Dias G, Marshall DJ (2010) Does the relationship between offspring size and performance change across the life-history? Oikos 119:154-162

\%'Dea A (2005) Zooid size parallels contemporaneous oxygen isotopes in a large colony of Pentapora foliacea (Bryozoa). Mar Biol 146:1075-1081

O'Dea A, Okamura B (1999) Influence of seasonal variation in temperature, salinity and food availability on module size and colony growth of the estuarine bryozoan Conopeum seurati. Mar Biol 135:581-588

* O'Dea A, Okamura B (2000) Life history and environmental inference through retrospective morphometric analysis of bryozoans: a preliminary study. J Mar Biol Assoc UK 80:1127-1128

O'Dea A, Jackson JBC, Fortunato H, Smith JT, D'Croz L, Johnson KG, Todd JA (2007) Environmental change preceded Caribbean extinction by 2 million years. Proc Natl Acad Sci USA 104:5501-5506

\% Okamura B, Bishop JDD (1988) Zooid size in cheilostome bryozoans as an indicator of relative palaeotemperature. Palaeogeogr Palaeoclimatol Palaeoecol 66:145-152

* Orr RJS, Waeschenbach A, Enevoldsen ELG, Boeve JP and others (2018) Bryozoan genera Fenestrulina and Micro- 
porella no longer confamilial; multi-gene phylogeny supports separation. Zool J Linn Soc 186:190-199

Pettersen AK, White CR, Bryzon-Richardson RJ, Marshall DJ (2019) Linking life-history theory and metabolic theory explains the offspring size-temperature relationship. Ecol Lett 22:518-526

Raff EC, Villinski JT, Turner FR, Donoghues PCJ, Raff RA (2006) Experimental taphonomy shows the feasibility of fossil embryos. Proc Natl Acad Sci USA 103: 5846-5851

Ramirez Llodra E (2002) Fecundity and life-history strategies in marine invertebrates. Adv Mar Biol 43:87-170

R Core Team (2019) R: a language and environment for statistical computing. R Foundation for Statistical Computing, Vienna. www.r-project.org

Ryland JS (1963) The species of Haplopoma (Polyzoa). Sarsia 10:9-18

Stearns SC (1992) The evolution of life histories. Oxford University Press, Oxford

Strathmann RR, Strathmann MF (1982) The relationship

Editorial responsibility: Steven Morgan,

Bodega Bay, California, USA

Reviewed by: S. Hageman and 2 anonymous referees between adult size and brooding in marine invertebrates. Am Nat 119:91-101

Strathmann RR, Strathmann MF, Emson RH (1984) Does limited brood capacity link adult size, brooding, and simultaneous hermaphroditism? A test with the starfish Asterina phylactica. Am Nat 123:796-818

Taylor PD, Mawatari SF (2005) Preliminary overview of the cheilostome bryozoan Microporella. In: Moyano GHI, Cancino JM, Wyse Jackson PN (eds) Bryozoan studies 2004. A. A. Balkema, Leiden, p 329-339

* van Hinsbergen DJJ, de Groot LV, van Schaik SJ, Spakman W and others (2015) A paleolatitude calculator for paleoclimate studies (model version 2.1). PLOS ONE 10:e0126946

*Yagunova EB, Ostrovsky AN (2010) The influence of substrate type on sexual reproduction of the bryozoan Cribrilina annulata (Gymnolaemata, Cheilostomata): a case study from Arctic seas. Mar Biol Res 6:263-270

Zuur A, Ieno E, Elphick C (2010) A protocol for data exploration to avoid common statistical problems. Methods Ecol Evol 1:3-14

Submitted: October 26, 2020

Accepted: January 28, 2021

Proofs received from author(s): March 3, 2021 